\title{
Thymic neuroendocrine tumor: About a rare clinical case and review of literature
}

\author{
Rajae Najib, Daoudi Khaoula, Zineb Benbrahim, Nezar Bouyahia, Samia Arifi, Nawfel Mellas \\ Medical Oncology Department, HASSAN II University Hospital, FEZ, MOROCCO \\ Correspondence: Daoudi Khaoula. Address: Medical Oncology Department, HASSAN II University Hospital, FEZ, \\ MOROCCO. BP 7206, FES ZOHOR, 30014 FEZ, Morocco. Email: khaoula.med06@gmail.com
}

Received: December 15, 2013

Accepted: June 18, 2014

Online Published: October 5, 2014

DOI : $10.5430 /$ jst.v4n3p33

URL: http://dx.doi.org/10.5430/jst.v4n3p33

\begin{abstract}
Neuroendocrine carcinomas of the thymus are uncommon, less than 200 cases have been described in the literature. Some previous studies indicate that these tumors may have a more aggressive behavior than their pulmonary counterparts with a poor response to chemotherapy for metastatic cases. In this paper, we report an atypical neuroendocrine carcinoma of the thymus associated with lymph node metastases and we analyze different data about diagnosis and treatment of this rare entity.
\end{abstract}

\section{Key words}

Thymic, Neuroendocrine, Carcinoma, Chemotherapy

\section{I ntroduction}

Thymic neuroendocrine carcinomas are unusual thymic neoplasms representing less than $5 \%$ of anterior mediastinal tumors and $1.8 \%$ of neuroendocrine tumors ${ }^{[1,2]}$. Their evaluation is similar to that of primary pulmonary neuroendocrine tumors. NECs are often locally aggressive. About thirty percent of patients have distant metastases of their tumors ${ }^{[3]}$. Their evolution is more pejorative than other sites ${ }^{[4]}$.

\section{Case presentation}

A 54-year-old man, a heavy smoker, without previous history of multiple endocrine neoplasia, presented with right chest pain, progressive dyspnea lasting for 3 months, but with conservation of the general state. Thoracoabdominopelvic computed tomography showed an extensive right mediastinal tumor measuring $17 / 13 \mathrm{~cm}$ with pericardial effusion, a right pneumothorax and laterotracheal and retroperitoneal lymph nodes measuring $2.5 \mathrm{~cm}$ (Figure 1). The patient underwent a thoracic biopsy scan-guided allowed to positive diagnosis. Histological examination showed a proliferation arranged in layers and diffuse nappes, monomorphic cells with regular nuclei and fine chromatin with 20 mitoses per 10 fields and no area of necrosis. Vascularization was spindly and endocrine type (Figure 2). Immunohistochemical study showed positive reaction for CD56 and Chromogranin (Figure 3 and 4). Staining for CD5 and CD1a was negative. Based on histology and immunohistochemistry, the diagnosis was poorly differenciated neuroendocrine tumor of the thymus. The tumor was classified IVa according to the Masaoka staging of thymic neoplasms. Patient received three cycles of che- 
motherapy based on Carboplatin (AUC=5) + VP16 (120 mg/m² on 3 days), D1 = D21 with two episodes of hypercalcemia and progression of the process, the later tracheal and pelvic lymph nodes (Figure 5). Cytoreductive surgery and palliative radiotherapy were proposed but refused because of the extension and large tumor volume. Patient is still alive after 12 months of stopping of chemotherapy with a general state relatively conserved.

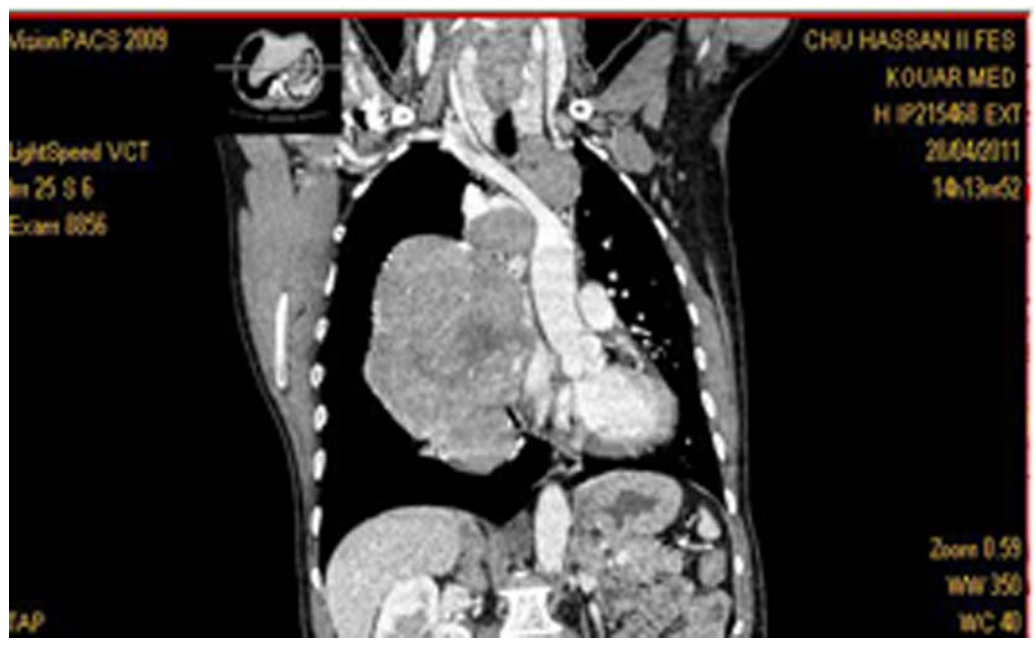

Figure 1. CT scan of the chest cut: extensive mediastinal tumor with laterotracheal lymph nodes

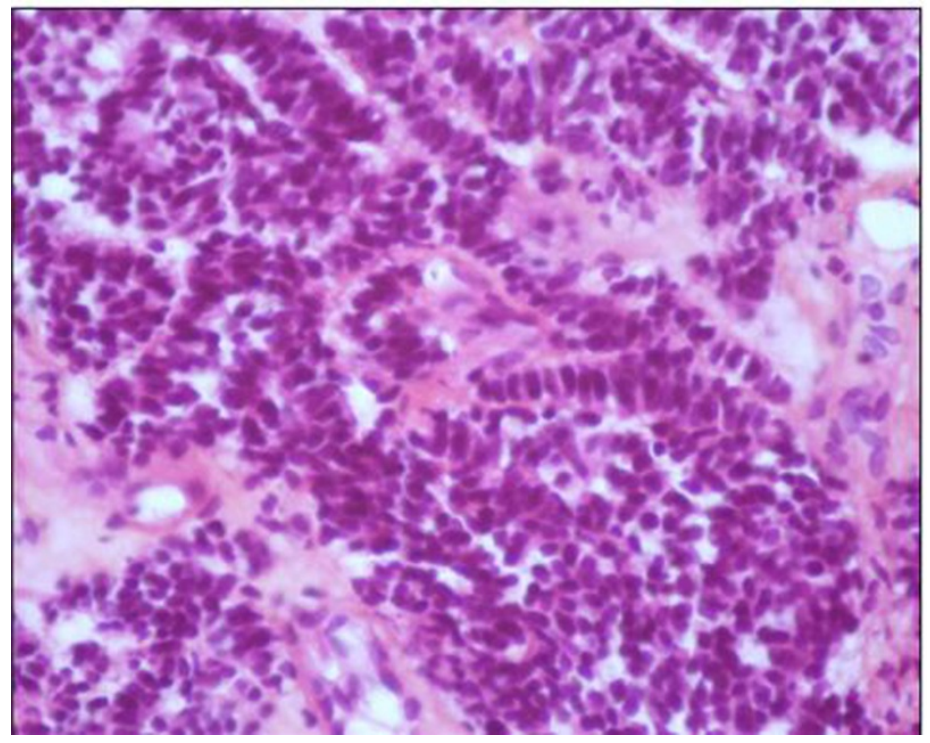

Figure 2. Scan guided biopsy of the mediastinum process: tumor cells are monomorphic with regular nuclei and fine chromatin with more than 2 mitoses per 10 fields (X50)

\section{Discussion}

Primary neuroendocrine neoplasms occurring in the mediastinum are rare. The spectrum of such tumors can range from low- to high-grade neoplasms ${ }^{[5]}$. The histological classification of thymic neuroendocrine tumors depends on tumor differentiation, presence or absence of necrosis and mitotic counts ${ }^{[6]}$. As our case, the neuroendocrine carcinoma of the thymus are located in the anterior mediastinum with a male predominance (sex ratio $\mathrm{M} / \mathrm{F}=3 / 1$ ). The average age of diagnosis is 43 years. Their discovery is fortuitous in $65 \%$ of cases, in other cases, symptoms are the consequences of mediastinal compression local ( dyspnea, superior vena cava syndrome, chest pain, etc.) ${ }^{[2]}$. Neuro endocrine carcinoma of 
the thymus may be seen as sporadic cases or be part in the MEN1 (Multiple endocrine neoplasia type 1) associated with endocrine symptoms, especially Cushing's syndrome, acromegaly or SIADH (syndrome of inappropriate antidiuretic hormone secretion) which occur in approximately thirty percent of the patients ${ }^{[7-9]}$. They are locally aggressive in the majority of cases with a high risk of relapse after surgery. Approximately, 30\%-40\% has distant metastases at diagnosis ${ }^{[10]}$. Our patient has intrathoracic and retroperitoneal lymph nodes metastases at the diagnosis. In our case, chest pain and dyspnea were the mainly symptoms with no endocrine symptoms. The classification of TNET (Thymic Neuro Endocrin Tumors) was much changed. Currently, it has, like other organs, two subtypes: well differentiated carcinomas and poorly differentiated carcinomas including CPC and CNEG ${ }^{[11]}$. The WHO also recognizes several morphological variants of thymic carcinoid as spindle cell carcinoid, carcinoid pigmented, carcinoid with amyloid deposits, the oncocytic carcinoid, mucinous carcinoid, carcinoid angiomatoïde, carcinoid with sarcomatous transformation and mixed carcinoid $^{[4]}$.

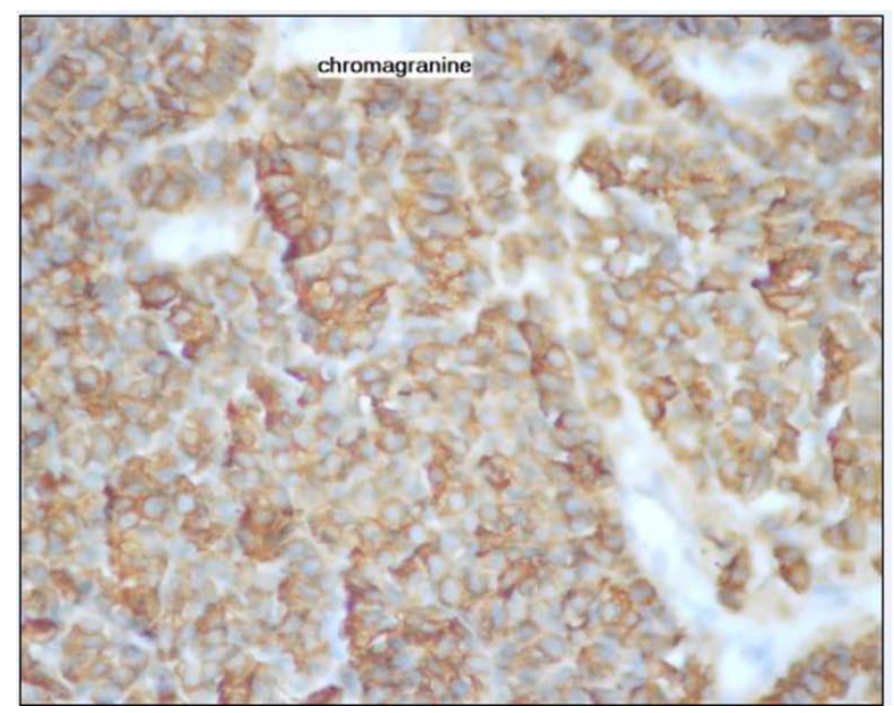

Figure 3. positive reaction for chromogranin in tumor cells(X50)

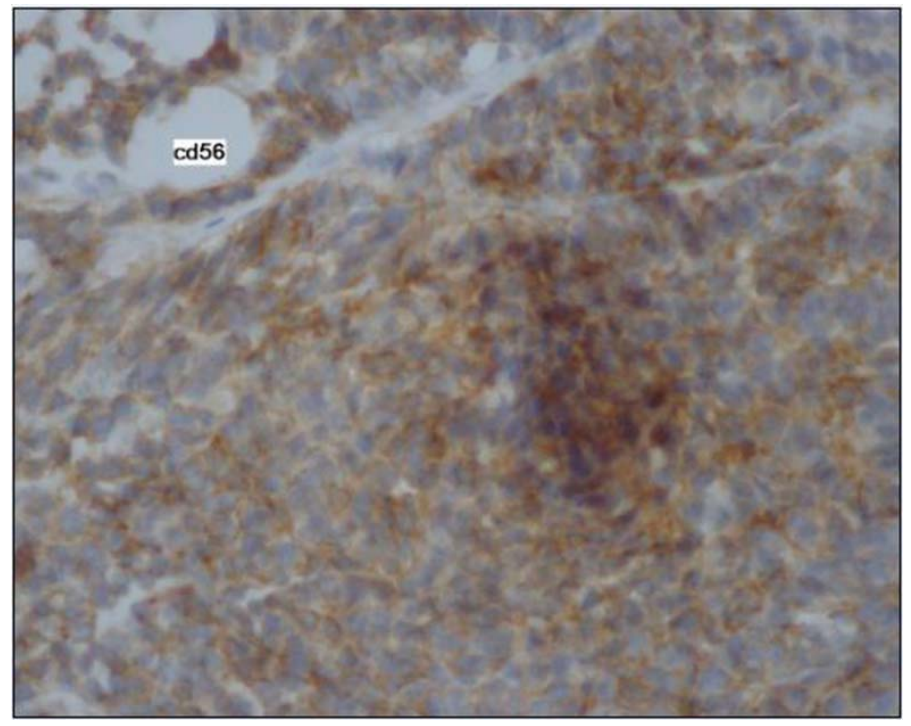

Figure 4. positive reaction for cd56 in tumor cells(X50)

The diagnosis of TNET based on morphological criteria is similar to neuroendocrine tumors of the lung ${ }^{[12]}$. Individualization in subtypes depends mainly on necrosis and / or the number of mitoses (less than 2 mitoses for typical 
carcinoid, from 2 to 10 mitoses for atypical carcinoid and more than 10 mitoses for CNEGC per 10 fields).The diagnosis of neuroendocrine carcinoma will be much confirmed by positive cytokeratin mainly low molecular weight (100\%) and neuroendocrine markers (chromogranin (75\%), synaptophysin (72\%), Leu-7 (68\%) ${ }^{[4]}$ ). In our case, neuroendocrine markers chromogranin and synaptophysin were positive. The biological diagnosis should include urinary cortisol, plasma ACTH and chromogranin A and B measurments. CT is the best diagnostic imaging investigation, for MRI it can be indicated to assess locoegional extension of the tumor and guide the surgical treatment procedure. In addition, scintigraphy with ${ }^{111}$ In-octreotide is valuable ${ }^{[10]}$.

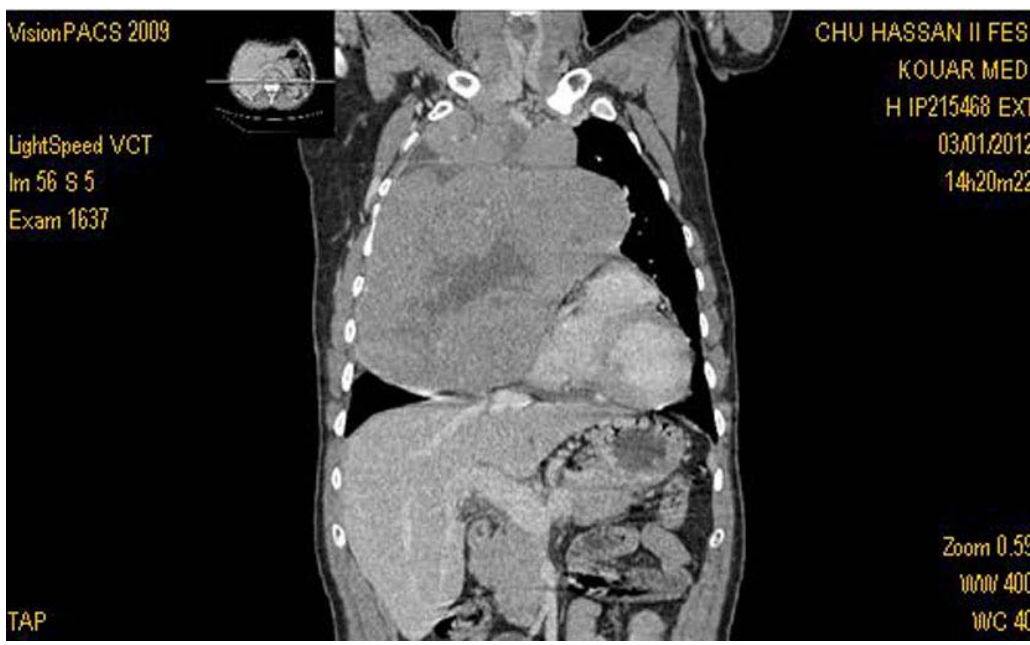

Figure 5. CT scan of the chest cut: progression of the mediastinal tumor

Surgery is the gold standard of the treatment with resection of both the tumor and intrathoracic lymph nodes. Adjuvant radiotherapy is indicated for incompletely excised tumor or lymph node involvement. Palliative radiotherapy can be proposed in superior vena cava syndrome. In case of high uptake on scintigraphy with ${ }^{111}$ In-octreotide, targeted radiotherapy with octreotide may be considered in patients with incompletely respectable tumors. Multiple chemotherapy protocols have been studied, including cisplatin/etoposide, streptozotocin/doxorubicin, ifosfamide/etoposide with the modest responses; the best results are obtained with a combination of cisplatin or carboplatin/etoposide ${ }^{[13]}$. Our case has received 3 cycles of chemotherapy based on carboplatin/Etoposide with progression of the disease. Other studies have shown that the temozolomide is an effective drug as mono-therapy, resulting in stabilization of the disease in 5/7 patients ${ }^{[9]}$. The prognosis of TNETS is very poor. Cases with MEN1 or Cushing's syndrome have the worse prognosis ${ }^{[10]}$. The prognosis appears identical to the other thymic carcinomas (15\% survival at 5 years) ${ }^{[14]}$. Quality of surgical resection is a major prognostic factor ${ }^{[15-17]}$, but the character invasiveness of these tumors rarely allows to complete surgery. The prognosis of well differentiated neuroendocrine carcinomas is more favorable. On atypical carcinoid, the median survival is 28 months ${ }^{[18]}$. The prognosis of thymic neuroendocrine carcinomas of is more pejorative than lung neuroendocrine tumors.

\section{Conclusion}

In summary, we experienced a case of TNET locally invasive with lymph nodes metastases. The diagnosis was confirmed by histology and immunohistochemical examinations, surgical resection was contraindicated because of the extension of the tumor, response to chemotherapy was poor.

\section{References}

[1] Ruffini E, Oliaro A, Novero D, Campisi P, Filosso P. Neuroendocrine Tumors of the Thymus. Thoracic Surg Clinics. 2011 February; 21(1): 13-23. http://dx.doi.org/10.1016/j.thorsurg.2010.08.013 
[2] Klemm KM, Moran CA. Primary neuroendocrine carcinomas of the thymus. Sem Diagn Pathol. 1999; 16(1): 32-41. PMid:10355652

[3] Wick MR. Neuroendocrine Neoplasms of the Thymus. Pathol - Resear and Practice. 1988 April;183(2): 188-199.

[4] Chalabreysse L, Gengler C, Sefiani S, Meyronet D. Les tumeurs neuroendocrines du thymus, À propos de 6 cas. Annales de Pathol. 2005 June; 25(3): 205-210.

[5] Cesar A. Moran. Neuroendocrine carcinomas of the mediastinum: review of current criteria for histopathologic diagnosis and classification. Seminars in Diagn Pathol. 2005 August; 22(3): 223-229.

[6] Neda Kalhor, Cesar A. Moran. Mediastinal neuroendocrine tumours. Diagnostic Histopathology. 2010 May; 16 (5): $237-242$. http://dx.doi.org/10.1016/j.mpdhp.2010.03.003

[7] Rosai J, Higa E, Mediastinal endocrine neoplasm of probable thymic origin related to carcinoid tumor. Cancer. 1972; 29: 1061-1074. http://dx.doi.org/10.1002/1097-0142(197204)29:4\%3C1061::AID-CNCR2820290456\%3E3.0.CO;2-3

[8] Lowenthal RM, Gumpel JM, Kreel L, McLaughlin JE, Skeggs BL. Carcinoid tumour of the thymus with systemic manifestations: a radiological and pathological study. Thorax. 1974; 92: 553-558. http://dx.doi.org/10.1136/thx.29.5.553

[9] Dan Granberg, Neuroendocrine tumours. Update on Cancer Therapeutics. 2007 March; 2(1): 41-52. http://dx.doi.org/10.1016/j.uct.2007.04.001

[10] Wick MR, Rosai J, Neuroendocrine neoplasms of the thymus. Pathol Res Pract. 1988; 183: 188-189. http://dx.doi.org/10.1016/S0344-0338(88)80046-3

[11] Moran CA, Suster S. Thymic neuroendocrine carcinomas with combined features ranging from well-differentiated (carcinoid) to small cell carcinoma: a clinicopathologic and immunohistochemical study of 11 cases. Am J Clin Pathol. 2000; 113: 345-350. http://dx.doi.org/10.1309/Q01U-60BL-VEV4-TWR1

[12] Travis WD, Brambilla E, Müller-Hermelink HK, Harris CC. Thymic neuroendocrine tumours. Tumours of the lung, pleural, thymus and heart. World Health Organization International Histological Classification of Tumours, 3nd edn. Berlin: Springer-Verlag; 2004.

[13] Fjällskog ML, Granberg DP, Welin SL,Eriksson C, Öberg KE,Janson ET et al. Treatment with cisplatin and etoposide in patients with neuroendocrine tumors. Cancer. 2001; 92: 1101-1107. http://dx.doi.org/10.1002/1097-0142(20010901)92:5\%3C1101::AID-CNCR1426\%3E3.0.CO;2-V

[14] Chalabreysse L, Etienne-Mastroianni B, Adeleine P, Cordier JF, Greenland T, Thivolet-Bejui F. Thymic carcinoma: a clinicopathological and immunohistological study of 19 cases. Histopathology. 2004; 44: 367-374. http://dx.doi.org/10.1111/j.1365-2559.2004.01796.x

[15] Gal AA, Kornstein MJ, Cohen C, Duarte IG, Miller JI, Mansour KA. Neuroendocrine tumors of the thymus: a clinicopathological and prognostic study. Ann Thorac Surg. 2001; 72: 1179-1182. http://dx.doi.org/10.1016/S0003-4975(01)03032-6

[16] Chalabreysse L, Etienne-Mastroianni B, Adeleine P, Cordier JF, Greenland T, Thivolet-Bejui F. Thymic carcinoma : a clinicopathological and immunohistological study of 19 cases. Histopathology. 2004; 44: 367-374. http://dx.doi.org/10.1111/j.1365-2559.2004.01796.x

[17] Chalabreysse L, Roy P, Cordier JF, Loire R, Gamondes JP, Thivolet-Bejui F. Correlation of the WHO schema for the classification of thymic epithelial neoplasms with prognosis: a retrospective study of 90 tumors. Am J Surg Pathol. 2002; 26: 1605-1611. http://dx.doi.org/10.1097/00000478-200212000-00008

[18] Fukai I, Masaoka A, Fujii Y, Yamakawa Y, Yokoyama T, Murase T et al. Thymic neuroendocrine tumor (thymic carcinoid): a clinicopathologic study in 15 patients. Ann Thorac Surg. 1999; 67: 208-211. http://dx.doi.org/10.1016/S0003-4975(98)01063-7 